\title{
Experimental Tests of How Hypothetical Monetary Lottery Incentives Influence Vaccine-Hesitant U.S. Adults' Intentions to Vaccinate
}

\author{
Jennifer M. Taber ${ }^{1}$, John A. Updegraff ${ }^{1}$, Pooja G. Sidney, ${ }^{2}$ Abigail G. O’Brien, ${ }^{1}$ \\ Clarissa A. Thompson ${ }^{1}$ \\ ${ }^{1}$ Department of Psychological Sciences, Kent State University \\ ${ }^{2}$ Department of Psychology, University of Kentucky
}

\begin{abstract}
Author Note
Jennifer M. Taber https://orcid.org/0000-0003-3285-4871

John Updegraff https://orcid.org/0000-0003-1128-3715

Pooja G. Sidney https://orcid.org/0000-0003-3719-8543

Clarissa A. Thompson https://orcid.org/0000-0001-8758-3218
\end{abstract}

We have no known conflict of interest to disclose.

Correspondence concerning this article should be addressed to Jennifer M. Taber, Kent State University, 358 Kent Hall, Kent, OH 44242-0001. Email: jtaber1@,kent.edu

This research was supported in part by the U.S. Department of Education Institute of Education Sciences Grants R305A160295 and R305U200004 to C. A. Thompson at Kent State University. 


\begin{abstract}
Background: In May, 2021, U.S. states began implementing "vaccination lotteries" to encourage vaccine-hesitant individuals to get a COVID-19 vaccine. Purpose: Drawing on theories from math cognition and behavioral economics, we tested several monetary lottery structures and their framing to determine which would best motivate unvaccinated individuals.

Methods: In two online experiments conducted in May, 2021, U.S. adults were asked to imagine that their state had implemented a vaccination lottery. In Experiment 1, participants $(n=589)$ were randomly assigned to 1 of 12 conditions that varied the monetary amount and number of winners, holding constant the total payout (\$5 million). In Experiment 2, participants $(n=274)$ were randomly assigned to 1 of 4 conditions in a 2 (Message Framing: Gain versus Loss) by 2 (Numeric Framing: 5 total winners versus 1 winner for 5 weeks) factorial design; in all four conditions, 5 people would each win $\$ 1$ million. Following the manipulation, participants rated their COVID-19 vaccination intentions, perceived likelihood of winning, and anticipated regret. Results: Vaccination intentions did not differ across conditions in either experiment, and postmanipulation vaccination intentions were strongly associated with baseline vaccination willingness. When asked to choose from 12 different lottery structures, participants tended to prefer options that awarded less money to more people, with $41.9 \%$ of participants across experiments indicated they would not vaccinate for any lottery-based monetary incentive.
\end{abstract} Conclusion: Findings suggest that multiple lottery structures could be equally motivating for unvaccinated adults, although states could consider structures that distribute incentives across more people.

Keywords: COVID-19, vaccination, lottery, financial incentive, message framing, whole number bias, 1-in-x effect 


\section{Introduction}

In May, 2021 — about 14 months after the beginning of a global pandemic_-vaccines for the novel coronavirus, COVID-19, received emergency authorization by the U.S. FDA and were recommended for U.S. individuals $12+$ years of age (1). To achieve herd immunity, an estimated $70 \%$ of the U.S. population would need to be vaccinated (2), but in May, 2021 only $47.1 \%$ of the total population had received at least one COVID-19 vaccine dose (3). To promote vaccination, on May 12, 2021, Ohio's governor announced that adults who were vaccinated could win \$1 million, with 1 winner selected each week for 5 weeks, for a total of 5 winners (4). It was initially termed a "regret lottery" (5); individuals registered themselves online, but if their name was chosen and they were unvaccinated, they could not win the money. Early media reports suggested that the lottery increased vaccination rates $(6,7)$. However, it was unknown whether the particular lottery structure chosen $-\$ 1$ million awarded to each of 5 people - would be the most likely to motivate people to vaccinate compared to other lottery structures totaling $\$ 5$ million in payouts. The goal of the present studies was to test the monetary lottery incentive structures (Experiment 1) and their framing (Experiment 2) that would lead to the greatest willingness to vaccinate among unvaccinated individuals. Importantly, these experiments provided the strongest test of which lottery structures unvaccinated U.S. adults would find motivating, given the inability to actually implement multiple lottery structures at scale.

\section{Would Monetary Lottery Incentives Motivate Vaccine-Hesitant Individuals?}

Within the health domain, financial incentives in the form of lotteries have successfully promoted health behaviors such as medication adherence $(8,9)$, physical activity $(10)$, and weight loss (11). Importantly, previous lotteries in health contexts differ from vaccine lotteries in at least two key ways: (1) they are typically used to promote behaviors about which people likely 
do not hold entrenched negative views, and (2) the amount of monetary incentives is substantially lower than that in the Ohio vaccination lottery (i.e., \$1 million).

\section{COVID-19 Vaccine Hesitancy}

Several studies conducted before COVID-19 vaccines were widely (12-15) found that common concerns among vaccine-hesitant adults were that development was rushed and vaccines were not adequately tested, and that there was insufficient long-term data on health consequences. Other reasons for hesitancy included concerns about immediate side-effects, preferring natural immunity, and doubting the vaccine's efficacy. Beliefs that COVID-19 is not severe were also associated with vaccine hesitancy (14), and people also reported a general lack of trust, both in vaccines and in the government (13).

Strong evidence does not exist for any particular strategies to decrease vaccine hesitancy, and few studies have specifically targeted people who were vaccine hesitant (16). Whether a monetary incentive would cause a person to vaccinate likely depends on the reasons underlying their hesitation, which monetary incentives do not address (17). For people who are indifferent or lack easy access, this type of incentive may change behavior. Conversely, for people who believe the vaccine will cause severe negative side effects, it is possible that no financial incentive would lead to vaccination and that better approaches would be to convince people that the vaccine was rigorously tested and of its safety (18).

\section{Experiment 1: What Lottery Structure Would Motivate Vaccine-Hesitant Individuals?}

The aim of Exp. 1 was to test how different monetary lottery structures allocating $\$ 5$ million across varying numbers of winners affected intentions to vaccinate among unvaccinated U.S. adults. Participants were randomly assigned to rate their vaccination intentions after viewing 1 of 12 lottery structures ranging from 500,000 people win $\$ 10$ each to 1 person wins $\$ 5$ 
million. These conditions were practically, rather than theoretically, motivated: $\$ 5$ million was the total payout in the Ohio vaccine lottery, the first publicized statewide vaccination lottery. Although all lottery structures yielded the same expected value, principles of math cognition and behavioral economics suggest that people may favor some structures over others. To accurately estimate likelihood of winning, a person would need to divide the number of winners (i.e., numerator) by the number of vaccinated people (i.e., denominator). But, this denominator is unknown and not mentioned. Even if it were mentioned, people dislike math (19), avoid math (20) and have general difficulty in reasoning with rational numbers, like fractions, ratios, and percentages $(21,22)$. People also overestimate and overweight very low probabilities (23-26), which is one reason people are drawn to state lotteries with extremely low probabilities but a large jackpot $(25,27)$. For these reasons, we expected that the number of winners would relate to perceived likelihood of winning, but also that people would most overestimate their likelihood of winning in conditions with the fewest winners. We also expected a diminishing effect of increasing either the number of winners or the amount of the award on motivation to vaccinate. For example, increasing the number of winners or the amount of the award from 10 to 50 would have a greater effect than increasing either from 50 to 100 . This phenomenon stems from constraints of the human perceptual system (Weber-Fechner law; (28)). Aside from these expectations, it was an open question as to whether people would value a lottery with more winners but a smaller monetary award, or fewer winners but a bigger monetary award. At the very least, we expected that there may be a monetary amount that most people would accept with certainty as an incentive for vaccinating, and people would exhibit greater willingness to vaccinate as the monetary amount approached that value, but a diminishing effect on willingness beyond that value. 


\section{How Should Vaccine Lotteries be Framed to Motivate Vaccine-Hesitant Individuals?}

A secondary goal was to test how to best describe lottery incentives to motivate vaccination. In Exp. 2 we tested different ways to describe the lottery structure of 5 people winning \$1 million each, which was Ohio’s lottery structure. First, we tested competing hypotheses as to whether describing 5 winners total or 1 winner for each of 5 weeks would lead to higher intentions to vaccinate; the latter reflected the framing of Ohio's initial vaccination announcement. Based on whole number bias $(29,30)$ and the size effect $(31)$, people may be more willing to vaccinate when the focus is 5 winners compared to 1 winner for 5 weeks because the perceived difference between small numbers (e.g., 5 vs. 1 winner) is greater than the perceived difference of equally distant larger numbers (e.g., 100,005 vs. 100,001) $(28,32)$. This occurs because perceived differences between numbers are governed by their ratio (i.e., 5 is 5 times bigger than 1) rather than absolute difference (i.e., 5 is 4 more winners than 1). On the other hand, research suggests that people overestimate their risk when it is described in a 1-in-X format (e.g., 1 in 4) relative to a $\mathrm{N}$-in- $\mathrm{X}^{*} \mathrm{~N}$ format (e.g., 3 in 12) $(33,34)$. In the context of an incentive lottery, learning that 1 person will win $\$ 1$ million dollars each week for the next 5 weeks - and thus emphasizing " 1 " person as the numerator - may make people overestimate their likelihood of winning the monetary award, and thus be more likely to vaccinate.

We also tested whether describing the lottery with a gain frame-emphasizing the positive outcomes of engaging in a behavior — or a loss frame-emphasizing the negative outcomes of not engaging in a behavior - influenced vaccination intentions. Rooted in prospect theory, a meta-analysis indicated that gain-framed messages led to greater engagement in prevention behaviors than loss-framed messages (although the effect size was small $(r=.083)$ (35). In general, evidence is mixed as to whether gain or loss frames more effectively promote 
vaccination specifically (36), and no work has addressed whether framing monetary payments for vaccination as gains or losses influences vaccination intentions.

\section{Anticipated Regret}

A secondary aim of both experiments was to examine the role of anticipated regret in predicting vaccination intentions and as a result of the manipulated conditions in both experiences. Anticipated regret is a strong predictor of willingness to play the lottery (37), and especially so for "regret lotteries" (38) in which people become attuned to the strong potential of experiencing and regretting a loss. People should be more motivated to avoid regret by taking an available action: in this case, by getting vaccinated. Such regret lottery structures successfully promoted weight loss in a prior randomized trial (11). In addition, anticipated regret (e.g., "If I don't get the flu shot and end up getting the flu, I'd be mad at myself for not getting the flu shot" (39)) is a strong predictor of vaccination (39-41). Here, we anticipated that loss frames would amplify anticipated regret in the context of regret lotteries.

\section{The Current Study}

We conducted two online experiments in May, 2021 in which unvaccinated U.S. adults were asked to imagine that the state they currently lived in was holding a lottery in which vaccinated individuals could win money. With the exception of hypothesizing that loss frames would lead to greater anticipated regret and that people would overestimate likelihood of winning the lottery, we did not have specific hypotheses about the effect of condition on vaccination intentions in either experiment. Given the potentially entrenched beliefs about vaccination, we did not want to extrapolate hypotheses based on data collected in "affect-poor" contexts that are less emotionally-charged (e.g., side-effects vs. monetary losses; cf. (42)). In addition to the primary outcome of intentions to vaccinate, we also assessed perceived likelihood 
of winning the lottery and anticipated regret as factors that might predict vaccination intentions. We also assessed attitudes about the COVID-19 vaccine and political affiliation (15). Further, to the extent that people base their decision of whether to vaccinate on the magnitude of the monetary incentive or the number of winners, we included several math-related variables that we expected would be related to perceived likelihood of winning and vaccination intentions.

\section{General Method}

\section{Overview}

We conducted two online experiments through Prolific, which allowed us to screen for people who were U.S. citizens, living in the U.S., 18 years of age or older, and who responded "no" to whether they had received the COVID-19 vaccine. Ohio's lottery was announced on

May 12, 2021 and data were collected from May 16-19, 2021. Data for both experiments were collected simultaneously, and people who completed Experiment 1 could not participate in Experiment 2. Across both studies, 5.6\% of participants (Exp. 1: $n=33$; Exp. 2: $n=15$ ) lived in Ohio. Electronic Supplemental Materials are available on OSF

\section{(https://osf.io/sxef7/?view_only=ba116890eeb5496eba1503a086ef6cc3). See Electronic}

Supplemental Materials (ESM Section I) for more information about exclusion criteria and Ohioans vs. non-Ohioans.

Sample sizes were determined based on multiple factors. First, funding and the number of potentially eligible respondents in Prolific (i.e., people who were not yet vaccinated) constrained our ability to power for small effect sizes. To maximize power while accounting for these constraints, we aimed to recruit samples large enough to identify a small-medium effect size of $f=0.17$. According to a priori power analyses conducted in $\mathrm{G}^{*}$ Power 3.1.9.2 (43) 600 people for Exp. 1 and 274 people for Exp. 2 were needed to detect differences across groups using ANOVA 
and given $a=0.05$ and power $=0.80$. Given the exploratory and time-sensitive nature of the study, we did not pre-register the experiments.

\section{Design and Procedure}

We complied with all relevant ethical regulations. The studies were approved by [blinded's] IRB. Participants who provided informed consent were randomly assigned to read about a vaccination lottery. The details varied across studies and conditions (described in "Manipulation"). Then, participants were asked to rate their willingness to vaccinate if the vaccine lottery was implemented. They also completed a set of dependent variables, individual differences, and demographic measures. Finally, participants were debriefed and provided with resources to learn more about COVID-19 vaccination.

All participants in both studies first read that, "Some states are giving incentives to people who receive the COVID-19 vaccine. Imagine that the following monetary incentive is announced for residents of the state you currently live in.” In Experiment 1, participants then read that, "Adults who have received at least their first dose of the vaccine have the chance to win \$X. Y winners will be announced. A lottery will draw a name from a pool of state residents. If your name is drawn as a winner, all you have to do to receive the money is show that you have been vaccinated." Participants were randomly assigned to 1 of 12 conditions in which the amount of money and the number of winners was systematically varied, but always totaled $\$ 5$ million. The specific conditions are shown in Figure 1.

In Experiment 2, participants were randomly assigned to one of four conditions in a 2 (Message framing: Gain vs. Loss) by 2 (Numeric framing: Small [1 winner each week for 5 weeks] vs. Big [5 total winners]) fully-crossed design. All participants read that 5 people would win $\$ 1$ million each. The gain frame condition stated that, "If your name is chosen and you are 
vaccinated, you WIN the money." The loss frame condition stated that, "If your name is chosen but you are not vaccinated, you CANNOT WIN the money." The small numeric frame condition stated that, "1 winner will be announced every week for 5 weeks" and the big numeric frame condition stated that, "5 winners will be announced."

\section{Measures}

The full text of all measures is available on OSF (https://osf.io/sxef7/?view_only=a1c32a0896e94c6da28c5bb9a3e12f00). Measures were the same in both studies and are described in the order they were administered. Additional details concerning measure selection and items not reported here are in ESM Section II.

Prior to the manipulation, participants read that, "All U.S. individuals aged 12 years and older are now recommended to receive a COVID-19 vaccine," and were asked to indicate baseline vaccination willingness, "How willing are you to get a COVID-19 vaccine?" Depending on the analysis, baseline willingness was treated either as continuous or dichotomized $(0=$ not at all/a little willing and 1=quite a bit/extremely willing) when retaining all four categories resulted in very small cell sizes when stratified by condition. Post-manipulation vaccination likelihood was assessed with two items, each prefaced with, "If your state offered this incentive." First, participants were asked, "How likely would you be to get a COVID-19 vaccine?" on a slider scale from "I definitely would NOT get vaccinated" (0) to "I definitely would get vaccinated" (100). Participants were not shown numeric options corresponding to the slider. Participants were then asked, "Would you get a COVID-19 vaccine?" with response options of yes or no. We refer to the former as vaccination intentions and the latter as vaccination decision. We use vaccination intentions in inferential analyses as a more sensitive measure and vaccination decision for descriptive purposes. An open-ended item asked participants to explain why they 
would or would not get a COVID-19 vaccine (data are beyond the scope of this paper, see (44)).

Participants were asked several questions to assess factors that might be influenced by condition. Perceived likelihood of winning was assessed with, "If you got vaccinated, how likely would you be to win the money?" on a slider scale from "Not at all" (0) to "Extremely" (100). Similar to the willingness to vaccinate slider question, participants could not see the numeric value. Anticipated regret was assessed with, "Imagine that your name is chosen as a winner, but you are not vaccinated and are not eligible to win. How much would you regret that you did not get a COVID-19 vaccine?" on a scale from 1 (not at all) to 4 (very much so) (40). To assess vaccine attitudes, participants completed 10 items on scales from 1 (strongly disagree) to 4 (strongly agree; see ESM Section III for full items). Three items assessed potential benefits of the COVID-19 vaccine (e.g., vaccine effectiveness) (45). One item assessed conspiracy beliefs: "Big Pharma is encouraging the spread of coronavirus to make money" (46). General COVID19-related medical mistrust was assessed with, "A lot of information is being held back by the government" (47). Two items assessed attitudes about vaccination in general: "Vaccination programs are a big con" and "Natural exposure to viruses and germs gives the safest protection" (48). One item assessed perceived COVID-19 severity on a scale from 1 (not at all severe) to 5 (very severe) (14). Next, participants were asked to consider possible positive or negative outcomes of COVID-19 vaccination and to type in the minimum amount of money they would need to receive to vaccinate, with an option of "No amount of money would be enough for me to get vaccinated.” Responses were capped at \$5 million for analyses.

In both experiments, participants then read that, "Some states are giving incentives to adults who receive the COVID-19 vaccine. Imagine that your state has 5 million dollars to give to people who get vaccinated. Which of the following monetary incentives would make you the 
most likely to get vaccinated?" Response options were the 12 vaccination lottery structures used in Exp. 1, presented in numeric order from more winners/less money to fewer winners/more money (see Figure 1) along with "None of the above--I would not get vaccinated." This item served as a within-subjects test of which lottery structure participants thought would be the most motivating when given the opportunity to compare and choose from among the lottery structures. They were then asked to provide a strategy report $(21,49)$ : "Please describe with as much detail as possible why you chose the monetary incentive option that you did."

Because people may try to calculate their likelihood of winning when reacting to the lottery structures, we included two math-related measures. Fraction equivalence was assessed with six items asking participants to indicate whether two presented fractions were equal (response options of "true" or "false") (50). The number of correct responses was summed to create a score of accuracy. Two items assessed general and fraction-specific math anxiety (51), on scales from 1 (not at all anxious) to 10 (very anxious).

Finally, participants reported demographic factors (see Table 1), including gender, race and ethnicity (coded as White $=1$, members of a different racial or ethnic group, biracial, or multiracial=0), education, income, and political orientation. Participants' state was captured by Prolific, and the population of adults aged 18 years and older as of July 1, 2019 for each participants' state was taken from the U.S. Census Bureau (52).

\section{Qualitative Coding}

Responses to the "strategy report" question were coded by authors JMT and AGO. Because of space limitations and the focus of this paper, we describe only data concerning explanations about the lottery structure, and not more general pro- or anti-vaccine responses (see (44) for a detailed analysis of negative responses to vaccine lotteries characterized as 
"backfiring" effects as well as concerns about the COVID-19 vaccine more broadly). See ESM Section $\mathrm{X}$ for a description of the coding process and the full coding scheme. Briefly, the coding process was iterative and involved double-coding about $48 \%$ of responses, with any ambiguous responses flagged for a second coder, and all disagreements discussed to reach 100\% agreement.

\section{Overview of Analyses}

After testing whether demographic variables were equally distributed across conditions, we report descriptive statistics for, and correlations among, the primary variables. We then used ANCOVAs to test whether condition, baseline vaccination willingness (dichotomized), and their interaction led to differences in post-manipulation vaccination intentions, controlling for gender in Exp. 1 because this variable was unequally distributed across conditions. Parallel analyses were tested with perceived likelihood of winning the lottery and anticipated regret as dependent variables. Then, we conducted a hierarchical linear regression to determine whether likelihood of winning and anticipated regret were associated with the dependent variable of vaccination intentions, controlling for other factors. We then collapsed across experiments and reported descriptive data concerning how much guaranteed money participants would need to vaccinate, which of the 12 lottery options would be most motivating, and participants' explanation for their choice of the most motivating vaccine lottery structures. In ancillary analyses, we examined bestfit non-linear relationships between the award amounts/number of winners on the outcomes of vaccine intentions, likelihood of winning, and anticipated regret given the logarithmic nature of the Weber-Fechner law and research in behavioral economics $(32,53)$; see ESM Section IV. All statistical tests were two-sided. Analyses did not adjust for multiple comparisons.

Collapsed across both experiments, about one-third of the sample indicated at baseline that they were not at all willing to vaccinate (Table $1 ; n=307$ of 863 ), and baseline willingness 
was strongly associated with post-manipulation intentions $(r s \geq 0.83$; see also ESM Section V for dependent variables stratified by baseline willingness). Although these 307 participants were largely opposed to vaccination regardless of any incentive, there was some variation: $35.8 \%$ indicated their post-manipulation vaccination intentions as greater than $0 \% ; 18.9 \%$ selected a lottery structure that they indicated would be the most motivating; and 31.8\% typed in an amount of money that they would vaccinate for. We considered reporting the primary analyses excluding these respondents, but due to this variation in responses within this group and because we did not predict a priori that this group would differ so strongly from others, we instead report the results of analyses excluding these "unwilling" participants in ESM Section VI.

\section{Experiment 1: Vaccine Lottery Structures}

\section{Participants}

Participant characteristics $(n=589)$ are shown in Table 1: the mean age was 34 , slightly under half of participants were male, and most (71.8\%) were White.

\section{Results and Discussion}

\section{Preliminary Analyses}

With the exception of gender, $\chi^{2}(11)=23.59, p=.015$, no sociodemographic or baseline variables significantly differed across conditions (all other $p \mathrm{~s}>.083$ ). Thus, gender (male $=1$, female or nonbinary $=0$ ) was included as a covariate in analyses with condition as a predictor. Table 2 shows the overall descriptive statistics for the dependent variables. On average, participants rated their intentions to vaccinate based on the lottery incentive shown to them as 37.6 out of 100 . Only $37.2 \%(n=219)$ said that they would vaccinate when asked to select "yes" or "no." Across conditions, participants rated their likelihood of winning as $13.8 \%$, and expected to feel "a little" regret if their name was chosen, but they were not vaccinated, $M=2.25$. 
Zero-order correlations among condition, the dependent variables, baseline willingness, and demographic factors are shown in Table 2. Condition was not significantly associated with post-manipulation vaccination intentions, but was negatively associated with perceived likelihood of winning and positively associated with anticipated regret. The latter three variables were all significantly positively associated. Those who reported greater post-manipulation vaccination intentions were more politically liberal, younger in age, more likely to be male, and had greater general and fraction-specific math anxiety and fraction equivalence knowledge. ESM Section III presents correlations among baseline willingness, post-manipulation vaccination intentions, and vaccine attitudes and perceived COVID-19 severity, which were all significantly correlated.

\section{Effect of Condition on Outcomes}

Post-manipulation vaccination intentions. We used ANCOVA to test the effect of condition (treated as a 12-level categorical variable) on post-manipulation vaccination intentions, with baseline willingness $(0=$ not at all/a little, $1=$ quite a bit/extremely) as a factor in the design and gender as a covariate. Vaccination intentions did not differ across condition, $F(11,561)=$ $1.29, p=0.224, \eta p^{2}=.03$. The condition by baseline willingness interaction was not significant, $F(11,561)=0.67, p=0.768, \eta p^{2}=.01$ (Figure 1a). Greater baseline willingness was associated with greater vaccination intentions post-manipulation, $F(1,561)=1083.72, p<0.001, \eta p^{2}=.66$. The main effect of gender was not significant, $F(1,561)=3.78, p=0.052, \eta p^{2}=.01$.

From an applied perspective, because the lottery structure implemented in Ohio was that 5 people would each win $\$ 1$ million, we examined pairwise comparisons between this condition and the 11 others. Collapsing across all participants, vaccination intentions were higher in the "5 people win $\$ 1$ million” condition than 3 others: "1 person wins $\$ 5$ million," $p=.048$; "50,000 
people win $\$ 100, " p=.013$; and “ 500,000 people win $\$ 10, " p=.036$. Within each category of baseline willingness, no pairwise comparisons were statistically significant at $p<.05$.

When vaccine intentions were modeled as a non-linear function of the monetary amount, the best fit for participants high in baseline vaccination willingness was a log function corresponding to an increasing, but diminishing, marginally significant influence of the monetary amount. For participants low in baseline willingness, the best fit was a quadratic function with a peak at \$1 million and a negative relationship from \$1 million to \$5 million. See ESM Section IV for additional information.

Perceived likelihood of winning the lottery. An ANCOVA controlling for gender and the population of each participant's state tested whether perceived likelihood of winning differed as a function of condition, baseline vaccination willingness, and their interaction. As shown in Figure $1 \mathrm{~b}$, perceived likelihood of winning significantly differed by condition, $F(11,560)=5.93$, $p<.001, \eta p^{2}=.01$ : conditions with more winners elicited greater perceived likelihood. A log function best fit the association between number of winners and perceived likelihood of winning for participants high in baseline vaccination willingness. A cubic function was the best fit for those low in baseline willingness (see ESM Section IV). Based on the ANCOVA, lower baseline willingness was associated with lower perceived likelihood of winning, $F(1,560)=55.68$, $p<.001, \eta p^{2}=.09$. Neither gender, $F(1,560)=2.26, p=.133, \eta p^{2}=.004$, nor state population were associated with likelihood of winning, $F(1,560)=0.07, p=.785, \eta p^{2}=.000$. The condition by baseline willingness interaction was not significant, $F(11,560)=1.64, p=.084, \eta p^{2}=.03$.

Anticipated regret. An ANCOVA controlling for gender tested whether anticipated regret differed as a function of condition, baseline vaccination willingness, and their interaction. As shown in Figure 1c, anticipated regret significantly differed by condition, $F(11,561)=5.99$, 
$p<.001, \eta p^{2}=.11$, such that conditions with higher monetary awards elicited greater anticipated regret. A log function best fit the association between monetary amount and anticipated regret for participants high and low in baseline willingness (see ESM Section IV). Based on the ANCOVA, lower baseline willingness was associated with less anticipated regret, $F(1,561)=$

365.93, $p<.001, \eta p^{2}=.40$. The condition by baseline willingness interaction was not statistically significant, $F(11,561)=1.41, p=.165, \eta p^{2}=.03$.

\section{Regression Predicting Vaccination Intentions}

Finally, we conducted a hierarchical linear regression to test whether perceived likelihood of winning and anticipated regret were associated with greater post-manipulation vaccination intentions, controlling for other factors. The full set of predictors and associated statistics are shown in ESM Section VIII. When controlling for all other variables, people who perceived themselves as more likely to win the lottery, $B=0.34, \beta=0.16, p<.001$, and who anticipated greater regret, $B=10.97, \beta=0.34, p<.001$, reported greater vaccination intentions (ESM Section VIII). Both predictors remained statistically significant at $p<.001$ when baseline vaccination willingness was also entered in a previous step.

\section{Experiment 2: Message Framing and Numeric Framing}

\section{Participants}

Participant demographics $(n=274)$ are shown in Table 1: the average age was 34 , about $40 \%$ of respondents were male, and most participants $(72.6 \%)$ were White.

\section{Results and Discussion}

\section{Preliminary Analyses}

No demographic or baseline variables significantly differed across conditions (all $p s>$.114). Table 2 shows descriptive statistics for the dependent variables. Participants' average 
vaccination intentions across conditions were 40.9 out of 100, similar to Exp. 1 (37.6). Across conditions, $42.0 \%(n=114)$ said that they would vaccinate (37.2\% in Exp. 1). On average, participants rated the likelihood of winning as $9.7 \%$ of 100 , and expected to feel between "a little bit" and "quite a bit" of regret if their name was chosen, but they were unvaccinated, $M=2.69$. Zero-order correlations among the dependent variables, baseline willingness, and sociodemographic factors are shown in Table 2. Similar to Exp. 1, participants who expressed greater post-manipulation vaccination intentions also reported greater perceived likelihood of winning and greater anticipated regret. Those with greater vaccination intentions were more politically liberal and younger in age. ESM Section III presents correlations among vaccination intentions, vaccine attitudes, and perceived COVID-19 severity.

\section{Effect of Condition on Outcomes}

A series of 2 (Message Framing: Gain vs Loss) X 2 (Numeric Framing: Small vs Big) ANOVAs tested the effect of the condition on the outcomes of vaccination intentions, perceived likelihood of winning, and anticipated regret, with baseline vaccination willingness (not at all/a little vs. quite a bit/extremely) as a factor in the design.

Post-manipulation vaccination intentions. Vaccination intentions did not differ as a function of Message Framing, $F(1,266)=0.01, p=.940, \eta p^{2}=.000$, Numeric Framing, $F(1,266)=1.40, p=.237, \eta p^{2}=.01$, or their interaction, $F(1,266)=1.40, p=.238, \eta p^{2}=.01$. Participants who expressed greater baseline willingness also reported greater post-manipulation intentions, $F(1,266)=363.18, p<0.001, \eta p^{2}=.28$. None of the two-or three-way interactions of baseline willingness with condition were significant, all $p s>.334$. No pairwise comparisons reached statistical significance, although emphasizing 5 winners with a loss frame led to somewhat greater vaccination intentions, $M=54.44$, than emphasizing 1 winner with a loss frame, 
$M=46.85 ; p=.089$, whereas gain frames with small, $M=50.45$, versus big, $M=50.46$, numeric framing led to similar levels of vaccination intentions, $p=.999$.

Perceived likelihood of winning the lottery. An ANCOVA controlling for the population of each participant's state tested whether perceived likelihood of winning differed as a function of Message Framing, Numeric Framing, baseline willingness, and all higher-order interactions. There were no main effects of Message Framing, $F(1,265)=0.61, p=.438, \eta p^{2}=.002$, or Numeric Framing, $F(1,265)=0.63, p=.428, \eta p^{2}=.002$, and no significant effect of their interaction, $F(1,265)=1.20, p=.274, \eta p^{2}=.10$. There were no significant condition by baseline willingness interactions (all $p s>0.071$ ). State population was not associated with perceived likelihood of winning, $F(1,265)=0.01, p=.928, \eta p^{2}=.000$. For participants with low baseline willingness, when a loss frame was used, emphasizing 5 winners led to greater perceived likelihood of winning, $M=15.03$, than emphasizing 1 winner over 5 weeks, $M=7.24, p=.045$, with no differences across Numeric Framing when a gain frame was used, $p=.276$. No other pairwise comparisons were significant as a function of baseline willingness or collapsed across baseline willingness (overall means: Gain/Small Framing: $M=10.15$; Gain/Big Framing, $M=9.47$; Loss/Small Framing, $M=9.44$; Loss/Big Framing, $M=13.69$ ).

Anticipated regret. Contrary to hypotheses, an ANOVA indicated no significant main effects of Message Framing, $F(1,266)=0.02, p=.887, \eta p^{2}=.000$, or Numeric Framing, $F(1,266)=$ $0.06, p=.807, \eta p^{2}=.000$, and no significant interaction, $F(1,266)=2.90, p=.090, \eta p^{2}=.01$. There were no significant condition by baseline willingness interactions, all $p s>0.312$, and no pairwise comparisons were statistically significant (Gain/Small Framing: $M=2.96$; Gain/Big Framing, $M=2.76$; Loss/Small Framing, $M=2.74$; Loss/Big Framing, $M=3.02$ ).

\section{Regression Predicting Vaccination Intentions}


Similar to Exp. 1, we used hierarchical linear regression to test whether perceived likelihood of winning and anticipated regret were associated with greater vaccination intentions, controlling for other factors (see ESM Section VIII for full model and statistics). Consistent with Exp. 1, people who perceived themselves as more likely to win the lottery, $B=0.34, \beta=0.15$, $p<.001$, and who anticipated greater regret, $B=9.48, \beta=0.30, p<.001$, reported greater postmanipulation vaccination intentions. Both predictors remained statistically significant at $p<.001$ when baseline willingness was also entered in a previous step.

\section{Experiments 1 and 2 Combined}

We conducted a subset of primarily descriptive analyses collapsed across Experiments 1 and 2.

\section{Money Needed to Vaccinate and Within-Subjects Choice of Vaccine Lottery Structure}

When asked how much money they would need to vaccinate, $30.8 \%$ of respondents ( $n=266$ of 863 ) stated no amount of money would motivate them to vaccinate. Among those who provided a value $(n=597)$, the modal response was $\$ 1,000$ (median $=\$ 500$, range $=\$ 0$ to $\$ 5$ million; responses were capped at $\$ 5$ million, although 22 respondents reported values $>\$ 5$ million). Overall, $10.9 \%(n=94$ of 863$)$ said they would vaccinate for $\leq \$ 10,15.6 \%(n=135)$ for $\$ 11-\$ 100$, and $20.4 \%(n=176)$ for $\$ 101-\$ 2,000$, and $22.2 \%(n=192)$ for $>\$ 2,000$.

Participants were shown a list of all 12 possible lottery structures and asked to choose which would most motivate them to vaccinate. As shown in Figure 2, participants' choice differed as a function of baseline willingness, $\chi^{2}(12)=355.11, p<.001$, and indicated a preference for more people winning less money. About 2 of 5 respondents $(41.9 \%, n=361$ of 862 ) indicated that they would not vaccinate in response to any lottery structure.

About 1 in 4 respondents $(26.3 \%, n=227)$ said that they would not vaccinate either for a 
guaranteed amount of money or in response to any vaccine lottery structure. Among people who said they needed $<\$ 2000$ to vaccinate, their selected lottery structure closely matched their required guaranteed amount. People who required $>\$ 2000$ overwhelmingly said no lottery structure would motivate them to vaccinate (see ESM Section IX).

\section{Open-Ended Strategy Reports for Within-Subjects Choice among Lottery Structures}

Participants were asked to explain their choice of the lottery structure that would most motivate them. Only $3.1 \%$ of participants $(n=27)$ mentioned the "denominator"- the number of vaccinated individuals eligible to win in their state - which is the number that would be required to calculate one's likelihood of winning. We stratified responses as a function of those who versus did not select an option (ESM Section X). Among those who selected a lottery structure, $40.5 \%$ reported considering the trade-offs between the amount of money and number of winners, compared to participants who mentioned either the amount of money $(26.7 \%)$ or the number of winners/their perceived likelihood of winning (17.0\%) as primarily driving their decision. As an indication of converging evidence between strategy reports and preferred lottery structure, the factors people mentioned as more motivating differed as a function of their lottery structure choice (Figure 3; ESM Section X). A subset of respondents chose a lottery structure but stated they would vaccinate regardless of any incentive (9.2\%) and/or described prosocial motivations reflecting a desire for the awards to help more people (7.6\%). Among those who did not choose a lottery structure, the most common explanation was low perceived likelihood of winning (28.8\%), followed by backfiring responses (19.1\%; see (44) for an in-depth analysis of these responses), and stating that the monetary award was low (12.5\%).

\section{Discussion}

Data from two experiments with samples of U.S. adults who were unvaccinated in May, 
2021, provided mixed evidence concerning the likely success of vaccine lotteries. Across experiments and conditions, only $38.6 \%$ of respondents said they would vaccinate in response to the vaccine lottery they read about. Importantly, vaccination intentions did not significantly differ across experimentally-manipulated vaccine structure (Exp. 1) or gain/loss message framing or big/small numeric framing (Exp. 2). Further, about 1 in 4 respondents said they would not vaccinate either for any guaranteed amount of money or in response to any of 12 possible vaccine lottery structures.

Results have implications for implementing similar incentives in other contexts involving emotionally-charged behavior. A comparison of vaccination rates in Ohio versus other U.S. states concluded that not only did rates in Ohio fail to increase after the lottery was announced, but given that vaccination rates were already declining, the rate of decline in vaccinations after May 12 was actually steeper in Ohio than in other U.S. states (54). Our data build on this by suggesting that other lottery structures totaling $\$ 5$ million in payouts are unlikely to have been more effective. In fact, when asked which of 12 lottery structures - all with the same total payout of \$5 million—would be most motivating, respondents tended to select options with more people winning less money. We place greater weight on the between-subjects experimental design as people are often unaware of factors that influence their behavior (55). However, given no differences in vaccination intentions across the experimentally-manipulated conditions, it may be worth considering that participants tended to prefer lottery structures giving more people less money. Although one-third of respondents indicated that no amount of guaranteed money would motivate them to vaccinate, the median response among those who would accept payment was $\$ 500$, with only $22 \%$ of the sample requiring more than $\$ 2,000$. Although this refers to a guaranteed payment, it suggests that some people may be willing to vaccinate for a chance at 
winning a smaller amount of money.

A second implication is that monetary incentives in the form of vaccine lotteries are unlikely to motivate people who are the most resistant to vaccination. Here, only 9 of 307 people who were "not at all" willing to vaccinate at baseline said that they would vaccinate in response to the manipulated hypothetical vaccine lottery they read about. If U.S. governmental money is spent on what are ostensibly public health initiatives, we argue that people with strong resistance to vaccination should not be "written off"; instead, it is important to know how they respond to vaccination interventions because they comprise an important subset of the target population (i.e., unvaccinated U.S. adults). One reason monetary incentives may not change behavior is that they do not target the reasons underlying vaccine hesitancy. Unvaccinated individuals have many concerns about the vaccine, commonly including health and safety concerns $(12,13,15)$, including in this dataset (44). Others have recommended that interventions promoting vaccination should be combined with evidence-based communication that addresses the underlying reasons for vaccine hesitancy (56). Specifically, communications should target mistrust and correct misperceptions, "in ways that affirm the audience's worldview or personal values" (56), p. 703. It may also be advantageous to appeal to emotional motives by counteracting negative emotions underlying vaccine hesitancy (57).

Despite the null effects of our experimental manipulations, perceived likelihood of winning the lottery and anticipated regret both strongly predicted vaccination intentions. Both factors also varied across the lottery structure conditions in Exp. 1, but in different directions: more money but fewer winners elicited both lower likelihood of winning and greater anticipated regret. Thus, these factors may work against each other in identifying an "optimal” lottery structure. Strategy report data provided converging evidence such that what people found 
motivating - i.e., the amount of money, likelihood of winning, or a trade-off between the twodiffered depending on the specific lottery structure they selected as the most motivating.

Several findings were consistent with research in math cognition. First, given adults' difficulty in accurately estimating the magnitude of ratios (50), it is unsurprising that people vastly overestimated their chances of winning. Even if only half of the $>9$ million adults living in Ohio as of July 1, 2019 (52) were vaccinated, with only 5 lottery winners, any particular individual's chance of winning was approximately $0.000056 \%$ ( 5 out of 9 million). Second, participants' reasoning about the size of the lottery incentives aligned with the Weber-Fechner Law, in which small values are overestimated relative to larger ones $(23,28)$. Among respondents with high baseline willingness to vaccinate, a logarithmic function was a better fit than other non-linear functions for the association between the manipulated lottery structure and all three dependent variables: vaccination intentions, likelihood of winning, and anticipated regret (ESM section IV). Importantly, the log function was a strong fit for likelihood and regret, but not a significant fit for vaccination intentions. Responses to the presented stimuli were more complex among respondents with low baseline willingness, suggesting they were not reasoning about the numeric information in the same way as those high in baseline willingness, or even at all.

In Exp. 2, vaccination intentions did not differ as a function of whether 1 winner for each of 5 weeks or 5 total winners was emphasized. This null effect may have occurred because people were more likely to spontaneously reinterpret 1 winner for each of 5 weeks as 5 total winners than we anticipated. Or, it may be because very large numbers are difficult to discriminate among (i.e., plateau of a logarithmic function (58)). Also in Exp. 2, vaccination intentions did not differ in response to gain or loss framing, consistent with prior findings that 
message framing did not influence COVID-19 vaccination intentions (59). Our hypothesis that loss frames would evoke greater anticipated regret was not supported. Although the loss frame was written to emphasize the feeling of "losing out" on an award and thus increase anticipated regret, even with gain framing, participants could have easily anticipated regret from not winning the lottery if they were unvaccinated. Further, given that no actual monetary losses would be incurred in either the gain or loss frame scenarios, any anticipated regret would likely be weaker than in situations in which the potential for actual loss motivates decision making via anticipated regret.

The current experiments employed the strongest design to answer how different lottery structures might affect intentions to vaccinate among vaccine-hesitant individuals. Data were collected within a week of the announcement of Ohio's vaccine lottery, which makes it less likely that participants were fatigued from, or influenced by, completing other similar vaccine lottery studies. Unfortunately, the sample size was not large enough to stratify as a function of the four categories of baseline willingness to vaccinate, as we did not predict a priori just how strongly baseline willingness would be associated with vaccination intentions after the manipulation. We were also underpowered to observe the small effect sizes seen in a metaanalysis of the effect of gain versus loss framing on prevention behaviors broadly (35). Results cannot necessarily generalize to participants in countries with different wealth distribution or political systems in place; in the U.S., the response to COVID-19 has been politicized and political ideology is associated with responses to the pandemic (60).

An analysis of actual vaccination rates in Ohio vs. other U.S. states before and after the announcement of Ohio's vaccine lottery on May 12, 2021 indicated that Ohio's vaccine lottery did not increase vaccination rates (54). The experimental approach we took provides further 
evidence that the particular lottery structure implemented by Ohio held no particular advantage. The lack of effects of experimentally-manipulated vaccine lottery structures on vaccination intentions suggests that multiple lottery structures could be equally motivating, with a quarter of unvaccinated U.S. adults indicating unwillingness to vaccinate in response to any guaranteed or lottery-based monetary incentive. However, self-reported preferences for lottery structures suggest that U.S. states could consider incentive structures that distribute monetary incentives more broadly. Alternatively, money may be better spent on other public health strategies, such as health communication campaigns that target the underlying reasons for vaccine hesitancy. 


\section{References}

1. Centers for Disease Control and Prevention. CDC Director Statement on Pfizer's Use of COVID-19 Vaccine in Adolescents Age 12 and Older. Available at https://www.cdc.gov/media/releases/2021/s0512-advisory-committee-signing.html. Accessibility verified July 6, 2021.

2. Fine P, Eames K, Heymann DL. "Herd immunity": A rough guide. Clin Infect Dis. 2011;52:911916.

3. Mayo Clinic. U.S. COVID-19 vaccine tracker: See your state's progress. Available at https://www.mayoclinic.org/coronavirus-covid-19/vaccine-tracker. Accessibility verified July 6, 2021. 4. @GovMikeDeWine. I know that some may say, "DeWine, you're crazy! This million-dollar drawing idea of yours is a waste of money." But truly, the real waste at this point in the pandemic -when the vaccine is readily available to anyone who wants it -- is a life lost to COVID-19. Posted May 12, 2021. Accessibility verified July 6, 2021.

5. Waldrop T. Others have tried free doughnuts, beers and gifts cards. Now, Ohio is betting millions to improve its vaccination rate. CNN. https://www.cnn.com/2021/05/13/us/covid-vaccineincentives/index.html. Accessibility verified July 6, 2021.

6. DeWine M. Don't roll your eyes at Ohio's vaccine lottery. The New York Times. Available at https://www.nytimes.com/2021/05/26/opinion/ohio-vaccine-lottery-mike-dewine.html. Accessibility verified July 6, 2021.

7. Hampton DJ. Ohio sees boost in shots after it announces $\$ 1$ million vaccination lottery. NBC. Available at https://www.nbcnews.com/news/us-news/ohio-sees-boost-shots-after-it-announces-1million-vaccination-n1267648. Accessibility verified July 6, 2021.

8. Kimmel SE, Troxel AB, Loewenstein G, et al. Randomized trial of lottery-based incentives to improve warfarin adherence. Am Heart J. 2012;164:268-274.

9. Volpp KG, Loewenstein $\mathrm{G}$, Troxel AB, et al. A test of financial incentives to improve warfarin adherence. BMC Health Serv Res. 2008; 8:1-6.

10. Patel MS, Volpp KG, Rosin R, et al. A randomized, controlled trial of lottery-based financial incentives to increase physical activity among overweight and obese adults. Am J Health Promot. 2018;32:1568-1575.

11. Volpp KG, John LK, Troxel AB, et al. Financial incentive-based approaches for weight loss: A randomized trial. JAMA. 2008;300:2631-2637.

12. Dodd RH, Pickles K, Nickel B, et al. Concerns and motivations about COVID-19 vaccination. Lancet Infect Dis. 2021;21:161.

13. Fisher KA, Bloomstone SJ, Walder J, et al. Attitudes toward a potential SARS-CoV-2 vaccine: A survey of US adults. Ann Intern Med. 2020;173:964-973.

14. Karlsson LC, Soveri A, Lewandowsky S, et al. Fearing the disease or the vaccine: The case of COVID-19. Pers Individ Dif. 2021;172:110590.

15. Latkin CA, Dayton L, Yi G, Konstantopoulos A, Boodram B. Trust in a COVID-19 vaccine in the US: A social-ecological perspective. Soc Sci Med. 2021;270:113684.

16. Dubé E, Gagnon D, MacDonald NE. Strategies intended to address vaccine hesitancy: Review of published reviews. Vaccine. 2015;33:4191-4203.

17. Largent EA, Miller FG. Problems with paying people to be vaccinated against COVID-19. JAMA. 2021;325:534-535.

18. Taylor S, Landry CA, Paluszek MM, et al. A proactive approach for managing COVID-19: The importance of understanding the motivational roots of vaccination hesitancy for SARS-CoV2. Front 
Psychol. 2020;11:2890.

19. Sidney PG, Thompson CA, Fitzsimmons C, Taber JM. Children's and adults' math attitudes are differentiated by number type. J Exp Educ. 2019;1-32.

20. Ashcraft MH, Kirk EP. The relationships among working memory, math anxiety, and performance. J Exp Psychol Gen. 2001;130:224.

21. Siegler RS, Thompson CA, Schneider M. An integrated theory of whole number and fractions development. Cogn Psychol. 2011;62:273-296.

22. Siegler RS, Fazio LK, Bailey DH, Zhou X. Fractions: The new frontier for theories of numerical development. Trends Cogn Sci. 2013;17:13-19.

23. Tversky A, Kahneman D. Advances in prospect theory: Cumulative representation of uncertainty. J Risk Uncertain. 1992;5:297-323.

24. Abdellaoui M. Parameter-free elicitation of utility and probability weighting functions. Manage

Sci. 2000;46:1497-1512.

25. Camerer CF. Chapter five: Prospect theory in the wild: Evidence from the field. In: Camerer CF, Loewenstein G, Rabin M. ed. Advances in behavioral economics: Princeton University Press, $2011 ; 148-161$.

26. Denes-Raj V, Epstein S. Conflict between intuitive and rational processing: When people behave against their better judgment. J Pers Soc Psychol. 1994;66:819.

27. Cook PJ, Clotfelter CT. The peculiar scale economies of lotto. Am Econ Rev. 1993;83:634-643.

28. Dehaene S. The number sense: How the mind creates mathematics. New York, NY: Oxford University Press. 2011.

29. Alibali MW, Sidney PG. Variability in the natural number bias: Who, when, how, and why. Learn Instr. 2015;37:56-61.

30. Ni Y, Zhou YD. Teaching and learning fraction and rational numbers: The origins and implications of whole number bias. Educ Psychol. 2005;40:27-52.

31. Dehaene S, Dehaene-Lambertz G, Cohen L. Abstract representations of numbers in the animal and human brain. Trends Neurosci. 1998;21:355-361.

32. Kahneman D, Tversky A. Prospect theory: An analysis of decision under risk. Econometrica. 1979;47:263-291.

33. Sirota M, Juanchich M, Bonnefon JF. "1-in-X" bias:"1-in-X" format causes overestimation of health-related risks. J Exp Psychol Appl. 2018;24:431.

34. Sirota M, Juanchich M, Kostopoulou O, Hanak R. Decisive evidence on a smaller-than-you-think phenomenon: Revisiting the "1-in-X" effect on subjective medical probabilities. Med Decis Making. 2014;34:419-429.

35. Gallagher KM, Updegraff JA. Health message framing effects on attitudes, intentions, and behavior: A meta-analytic review. Ann Behav Med. 2012;43:101-116.

36. Penţa MA, Băban A. Message framing in vaccine communication: A systematic review of published literature. Health Commun. 2018;33:299-314.

37. Sheeran P, Orbell S. Augmenting the theory of planned behavior: Roles for anticipated regret and descriptive norms. J Appl Soc Psychol. 1999;29:2107-2142.

38. Zeelenberg M, Pieters R. Consequences of regret aversion in real life: The case of the Dutch postcode lottery. Organ Behav Hum Decis Process. 2004;93:155-168.

39. Weinstein ND, Kwitel A, McCaul KD, et al. Risk perceptions: Assessment and relationship to influenza vaccination. Health Psychol. 2007;26:146-151.

40. Brewer NT, DeFrank JT, Gilkey MB. Anticipated regret and health behavior: A meta-analysis. Health Psychol. 2016;35:1264. 
41. Chapman GB, Coups EJ. Emotions and preventive health behavior: Worry, regret, and influenza vaccination. Health Psychol. 2006;25:82-90.

42. Suter RS, Pachur T, Hertwig R. How affect shapes risky choice: Distorted probability weighting versus probability neglect. J Behav Decis Mak. 2016;29:437-449.

43. Faul F, Erdfelder E, Lang AG, Buchner A. G* Power 3: A flexible statistical power analysis program for the social, behavioral, and biomedical sciences. Behav Res Methods. 2007;39:175-191. 44. [Blinded]. Backfiring Effects of Financial Incentives for COVID-19 Vaccination: "Vaccine Lotteries" Can Entrench and Exacerbate Negative Beliefs Among Vaccine-Hesitant U.S. Adults. Manuscript in preparation. 2021.

45. Daly M, Robinson E. Willingness to vaccinate against COVID-19 in the US: Representative longitudinal evidence from April to October 2020. Am J Prev Med. 2021;60:766-773.

46. Earnshaw VA, Eaton LA, Kalichman SC, et al. COVID-19 conspiracy beliefs, health behaviors, and policy support. Transl Behav Med. 2020;10:850-856.

47. Bogart LM, Ojikutu BO, Tyagi K, et al. COVID-19 related medical mistrust, health impacts, and potential vaccine hesitancy among Black Americans living with HIV. J Acquir Immune Defic Syndr. (1999). 2021;86:200.

48. Martin LR, Petrie KJ. Understanding the dimensions of anti-vaccination attitudes: The vaccination attitudes examination (VAX) scale. Annals Behav Med. 2017;51:652-660.

49. [Blinded]. Math matters during a pandemic: A novel, brief educational intervention combats whole number bias to improve health decision-making and predicts COVID-19 risk perceptions and worry across 10 days. Manuscript under review. 2020.

50. Fitzsimmons CJ, Thompson CA, Sidney PG. Do adults treat equivalent fractions equally? Adults' strategies and errors during fraction reasoning. J Exp Psychol: Learn, Mem, Cogn. 2020;46:2049. 51. Ashcraft MH. Math anxiety: Personal, educational, and cognitive consequences. Curr Dir Psychol Sci. 2002;11:181-185.

52. United States Census Bureau. Available at https://www.census.gov/quickfacts/OH . Accessibility verified July 6, 2021.

53. Furlong EE, Opfer JE. Cognitive constraints on how economic rewards affect cooperation. Psychol Sci. 2009;20:11-16.

54. Walkey AJ, Law A, Bosch NA. Lottery-based incentive in Ohio and COVID-19 vaccination rates. $J A M A$. Published online July 02, 2021

55. Nisbett RE, Wilson TD. Telling more than we can know: Verbal reports on mental processes.

Psychol Rev. 1977;84:231.

56. Finney Rutten LJ, Zhu X, Leppin AL, et al. Evidence-based strategies for clinical organizations to address COVID-19 vaccine hesitancy. Mayo Clin Proc. 2021;96:699-707.

57. Chou W-YS, Budenz A. Considering emotion in COVID-19 vaccine communication: Addressing vaccine hesitancy and fostering vaccine confidence. Health Comm. 2020;35:1718-1722.

58. Thompson CA, Siegler RS: Linear numerical-magnitude representations aid children's memory for numbers. Psychol Sci. 2010, 21:1274-1281.

59. Chen T, Dai M, Xia S, Zhou Y. Do messages matter? Investigating the combined effects of framing, outcome uncertainty, and number format on COVID-19 vaccination attitudes and intention. Health Comm. 2021:1-8.

60. Kerr J, Panagopoulos C, van der Linden S. Political polarization on COVID-19 pandemic response in the United States. Pers Individ Dif. 2021;179:110892. 
Table 1. Sociodemographic characteristics and baseline willingness to get a COVID-19 vaccine

\begin{tabular}{|c|c|c|}
\hline & $\begin{array}{c}\text { Experiment 1, } \\
n=589\end{array}$ & $\begin{array}{c}\text { Experiment 2, } \\
n=274\end{array}$ \\
\hline \multirow{2}{*}{ Age, years, M (SD) } & $34.3(11.5)$ & $33.9(11.8)$ \\
\hline & $\%($ (n) & $\%(n)$ \\
\hline \multicolumn{3}{|l|}{ Gender } \\
\hline Male & $44.1(260)$ & $39.8(109)$ \\
\hline Female & $53.5(315)$ & $58.0(159)$ \\
\hline Nonbinary or Different Identity & $1.9(11)$ & $1.4(4)$ \\
\hline Did not report & $0.5(3)$ & $0.7(2)$ \\
\hline \multicolumn{3}{|l|}{ Race and Ethnicity } \\
\hline Non Hispanic White & $71.8(423)$ & $72.6(199)$ \\
\hline Black or African American & $12.4(73)$ & $7.7(21)$ \\
\hline American Indian or Alaska Native & $0.5(3)$ & $0.4(1)$ \\
\hline Asian & $3.9(23)$ & $4.4(12)$ \\
\hline Native Hawaiian or Pacific Islander & $0.0(0)$ & $0.4(1)$ \\
\hline Hispanic or Latino $^{1}$ & $7.6(45)$ & $7.3(20)$ \\
\hline Selected more than one race or ethnicity & $3.1(18)$ & $4.7(13)$ \\
\hline Did not report or marked "different race or ethnicity" & $0.6(4)$ & $2.6(7)$ \\
\hline \multicolumn{3}{|l|}{ Education } \\
\hline High school diploma or GED or less & $21.4(126)$ & $23.4(64)$ \\
\hline Some college (no degree) or Associate's degree & $39.4(232)$ & $44.9(123)$ \\
\hline Bachelor's degree & $31.2(184)$ & $24.8(68)$ \\
\hline Graduate degree & $7.8(46)$ & $6.9(19)$ \\
\hline Did not report & $0.2(1)$ & $0.0(0)$ \\
\hline \multicolumn{3}{|l|}{ Household income } \\
\hline Under $\$ 15,00$ & $11.2(66)$ & $12.4(34)$ \\
\hline$\$ 15,000-\$ 24,999$ & $10.5(62)$ & $8.0(22)$ \\
\hline$\$ 25,000-\$ 34,999$ & $11.0(65)$ & $12.8(35)$ \\
\hline$\$ 35,000-\$ 49,999$ & $15.3(90)$ & $14.6(40)$ \\
\hline$\$ 50,000-\$ 74,999$ & $21.9(129)$ & $23.0(63)$ \\
\hline$\$ 75,000-\$ 99,999$ & $12.4(73)$ & $15.0(41)$ \\
\hline$\$ 100,000-\$ 149,999$ & $9.8(58)$ & $9.9(27)$ \\
\hline$\$ 150,000-\$ 199,999$ & $3.6(21)$ & $0.4(1)$ \\
\hline$\$ 200,000$ and higher & $1.7(10)$ & $0.7(2)$ \\
\hline Did not report & $2.5(15)$ & $3.3(9)$ \\
\hline \multicolumn{3}{|l|}{ Political orientation } \\
\hline Extremely liberal & $8.5(50)$ & $11.3(31)$ \\
\hline Liberal & $15.3(90)$ & $14.2(39)$ \\
\hline Slight liberal & $12.7(75)$ & $11.7(32)$ \\
\hline Moderate; middle of the road & $24.6(145)$ & $26.6(73)$ \\
\hline Slightly conservative & $12.1(71)$ & $10.6(29)$ \\
\hline Conservative & $17.8(105)$ & $14.2(39)$ \\
\hline Extremely conservative & $6.8(40)$ & $6.6(18)$ \\
\hline Did not report & $2.2(13)$ & $4.7(13)$ \\
\hline \multicolumn{3}{|l|}{ Baseline willingness to get a COVID-19 vaccine } \\
\hline Not at all & $37.4(220)$ & $31.8(87)$ \\
\hline A little & $30.1(177)$ & $33.6(92)$ \\
\hline Quite a bit & $16.0(94)$ & $16.8(46)$ \\
\hline Extremely & $16.6(98)$ & $17.9(49)$ \\
\hline
\end{tabular}

${ }^{1}$ Includes respondents who identified as White and Hispanic or Latino 
Table 2. Correlations among dependent variables, baseline vaccination willingness, and demographic and math-related variables. Experiment 1 above the diagonal, Experiment 2 below the diagonal.

\begin{tabular}{|c|c|c|c|c|c|c|c|c|c|c|c|c|c|}
\hline & $\begin{array}{c}\text { Post- } \\
\text { manipulation } \\
\text { vaccination } \\
\text { intentions }\end{array}$ & $\begin{array}{l}\text { Likelihood } \\
\text { of winning }\end{array}$ & $\begin{array}{c}\text { Anticipated } \\
\text { regret }\end{array}$ & $\begin{array}{c}\text { Baseline } \\
\text { vaccination } \\
\text { willingness }\end{array}$ & $\begin{array}{l}\text { General } \\
\text { math } \\
\text { anxiety }\end{array}$ & $\begin{array}{l}\text { Fraction } \\
\text { math } \\
\text { anxiety }\end{array}$ & $\begin{array}{c}\text { Fraction } \\
\text { equivalence }\end{array}$ & Education & Income & $\begin{array}{c}\text { Political } \\
\text { orientation }\end{array}$ & $\begin{array}{l}\text { Age, } \\
\text { years }\end{array}$ & Gender & Race \\
\hline Condition, Experiment $1^{\mathrm{a}}$ & 0.06 & $-0.24 * *$ & $0.25 * *$ & 0.02 & -0.01 & -0.02 & 0.01 & $0.09 *$ & -0.01 & -0.03 & 0.01 & -0.04 & 0.03 \\
\hline $\begin{array}{l}\text { Post-manipulation } \\
\text { vaccination intentions }\end{array}$ & -- & $0.33 * *$ & $0.74 * *$ & $0.88^{* *}$ & $0.14 * *$ & $0.09 *$ & $0.10^{*}$ & -0.03 & 0.06 & $-0.47 * *$ & $-0.20^{* *}$ & $0.12 * *$ & -0.04 \\
\hline Likelihood of winning & $0.26 * *$ & -- & $0.15 * *$ & $0.29 * *$ & $0.19 * *$ & $0.15^{* *}$ & -0.02 & -0.04 & -0.06 & $-0.23 * *$ & $-0.09 *$ & -0.03 & $-0.09 *$ \\
\hline Anticipated regret & $0.61 * *$ & 0.09 & -- & $0.68 * *$ & $0.16^{* *}$ & $0.11 *$ & $0.09 *$ & 0.01 & $0.10^{*}$ & $-0.39 * *$ & $-0.18^{* *}$ & $0.09^{*}$ & -0.03 \\
\hline $\begin{array}{l}\text { Baseline vaccination } \\
\text { willingness }\end{array}$ & $0.83 * *$ & $0.17 *$ & $0.55 * *$ & -- & $0.11 *$ & 0.06 & $0.09 *$ & -0.02 & 0.07 & $-0.49 * *$ & $-0.24 * *$ & $0.13 * *$ & -0.05 \\
\hline General math anxiety & 0.11 & 0.09 & $0.15^{*}$ & 0.07 & -- & $0.76^{* *}$ & $-0.27 * *$ & $-0.16 * *$ & $-0.18 * *$ & $-0.24 * *$ & $-0.08 *$ & $-0.26^{* *}$ & -0.05 \\
\hline Fraction math anxiety & 0.10 & $0.13 *$ & $0.17 * *$ & 0.05 & $0.74 * *$ & -- & $-0.35^{* *}$ & $-0.18 * *$ & $-0.18 * *$ & $-0.14 * *$ & -0.06 & $-0.29 * *$ & $-0.12 *$ \\
\hline Fraction equivalence & 0.03 & -0.01 & 0.09 & 0.08 & $-0.23 * *$ & $-0.32 * *$ & -- & $0.20^{* *}$ & $0.15 * *$ & 0.06 & -0.06 & $0.12 *$ & 0.02 \\
\hline Education & -0.01 & -0.07 & -0.01 & 0.01 & $-0.17 * *$ & $-0.20 * *$ & $0.32 * *$ & -- & $0.38 * *$ & $0.16^{* *}$ & $0.18^{* *}$ & 0.02 & 0.02 \\
\hline Income & -0.01 & $-0.17 *$ & 0.06 & 0.09 & -0.02 & -0.08 & $0.13 *$ & $0.19 * *$ & -- & $0.12^{*}$ & -0.01 & $0.08^{*}$ & -0.01 \\
\hline Political orientation & $-0.46^{* *}$ & $-0.16^{*}$ & $-0.33^{* *}$ & $-0.47 * *$ & $-0.15^{*}$ & $-0.14 *$ & 0.01 & 0.01 & 0.06 & -- & $0.23 * *$ & 0.05 & $0.23 * *$ \\
\hline Age, years & $-0.34 * *$ & -0.08 & $-0.34 * *$ & $-0.39 * *$ & 0.02 & 0.01 & -0.06 & 0.08 & -0.10 & $0.20 * *$ & -- & -0.06 & $0.17 * *$ \\
\hline Gender & -0.01 & $-0.13 *$ & 0.05 & 0.05 & $-0.25^{* *}$ & $-0.26^{* *}$ & 0.10 & 0.02 & 0.05 & $0.13^{*}$ & $-0.30^{* *}$ & -- & -0.10 \\
\hline Race & -0.06 & $-0.14 *$ & -0.07 & -0.10 & 0.01 & 0.01 & -0.09 & 0.01 & -0.02 & $0.18 * *$ & $0.20 * *$ & -0.11 & -- \\
\hline M (SD), Experiment 1 & $\begin{array}{c}37.56 \\
(39.10)\end{array}$ & $\begin{array}{c}13.80 \\
(18.60)\end{array}$ & $\begin{array}{c}2.25 \\
(1.23)\end{array}$ & $\begin{array}{c}2.12 \\
(1.09)\end{array}$ & $\begin{array}{c}4.52 \\
(2.96)\end{array}$ & $\begin{array}{c}4.74 \\
(3.05)\end{array}$ & $\begin{array}{c}4.28 \\
(1.22)\end{array}$ & $\begin{array}{c}2.26 \\
(0.88)\end{array}$ & $\begin{array}{c}4.34 \\
(2.03)\end{array}$ & $\begin{array}{c}3.99 \\
(1.74)\end{array}$ & $\begin{array}{l}34.25 \\
(11.49)\end{array}$ & $\begin{array}{c}0.44 \\
(0.50)\end{array}$ & $\begin{array}{c}0.72 \\
(0.45)\end{array}$ \\
\hline M (SD), Experiment 2 & $\begin{array}{l}40.87 \\
(39.05)\end{array}$ & $\begin{array}{r}9.66 \\
(17.89)\end{array}$ & $\begin{array}{c}2.69 \\
(1.24)\end{array}$ & $\begin{array}{c}2.21 \\
(1.08)\end{array}$ & $\begin{array}{c}4.72 \\
(2.94)\end{array}$ & $\begin{array}{c}4.97 \\
(3.09)\end{array}$ & $\begin{array}{c}4.29 \\
(1.25)\end{array}$ & $\begin{array}{c}2.15 \\
(0.86)\end{array}$ & $\begin{array}{c}4.22 \\
(1.90)\end{array}$ & $\begin{array}{c}3.84 \\
(1.76)\end{array}$ & $\begin{array}{l}33.91 \\
(11.80)\end{array}$ & $\begin{array}{c}0.40 \\
(0.49)\end{array}$ & $\begin{array}{l}0.73 \\
(0.45)\end{array}$ \\
\hline Range & $0-100$ & $0-100$ & $1-4$ & $1-4$ & $1-10$ & $1-10$ & $0-6$ & $1-4$ & $1-9$ & $1-7$ & $18-78$ & $0-1$ & $0-1$ \\
\hline
\end{tabular}

${ }^{a}$ Coded as a continuous variable from 1 to 12 , with smaller values indicating less money allocated to a greater number of people. Note. Condition for Experiment 2 is not included in this table because it cannot be treated as a continuous variable.

${ }^{*} p<.05, * * p<.005$ 
Figure 1a. Mean post-manipulation vaccination intentions (measured on a slider scale from 1-100, with higher values indicating greater willingness) as a function of the 12 experimentally-manipulated conditions in Experiment 1 and baseline vaccination willingness, controlling for gender

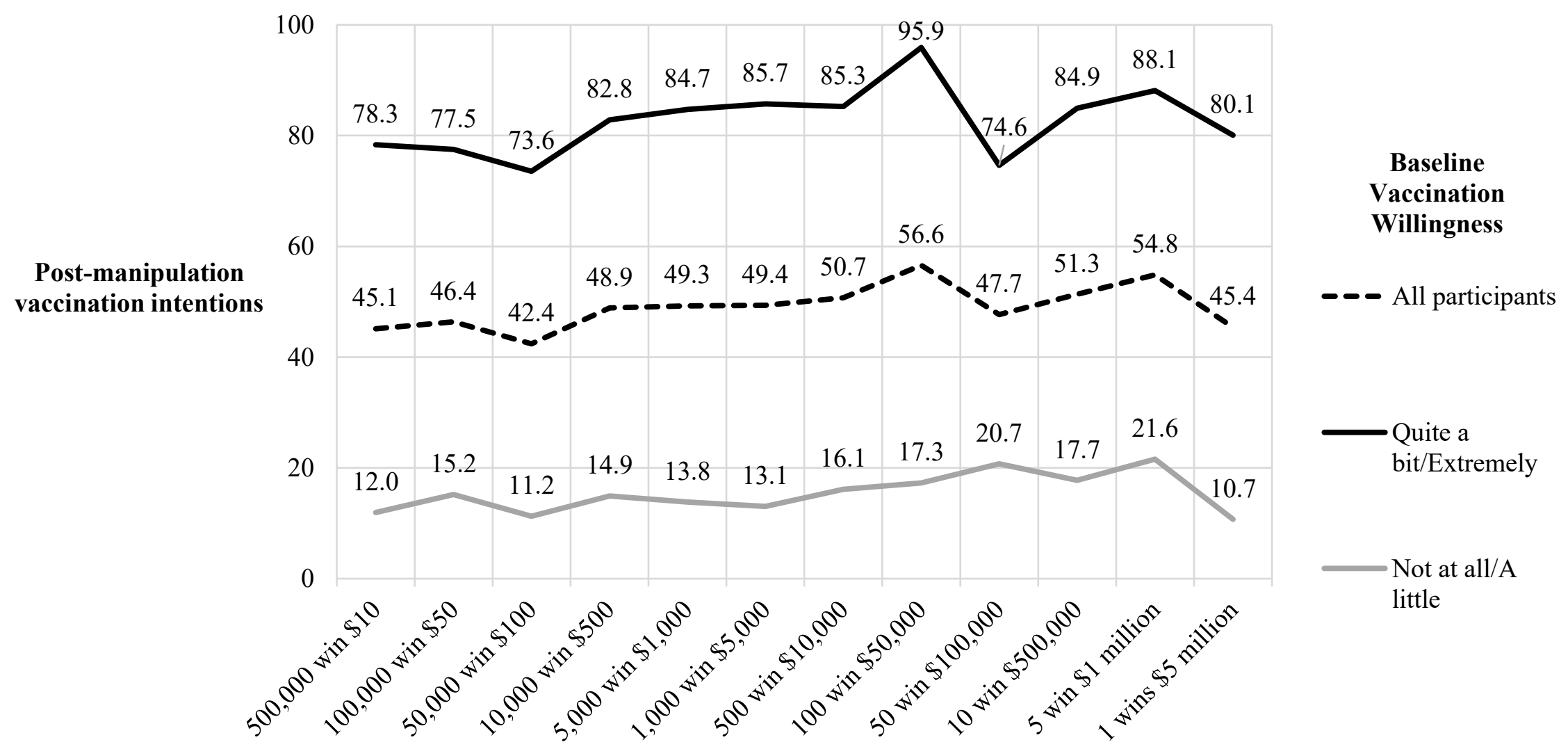

Experimentally-Manipulated Lottery Structure Condition 
Figure 1c. Experiment 1, mean likelihood of winning (measured on a slider scale from 1-100, with higher values indicating greater likelihood) as a function of the 12 experimentally-manipulated conditions and baseline willingness, controlling for gender

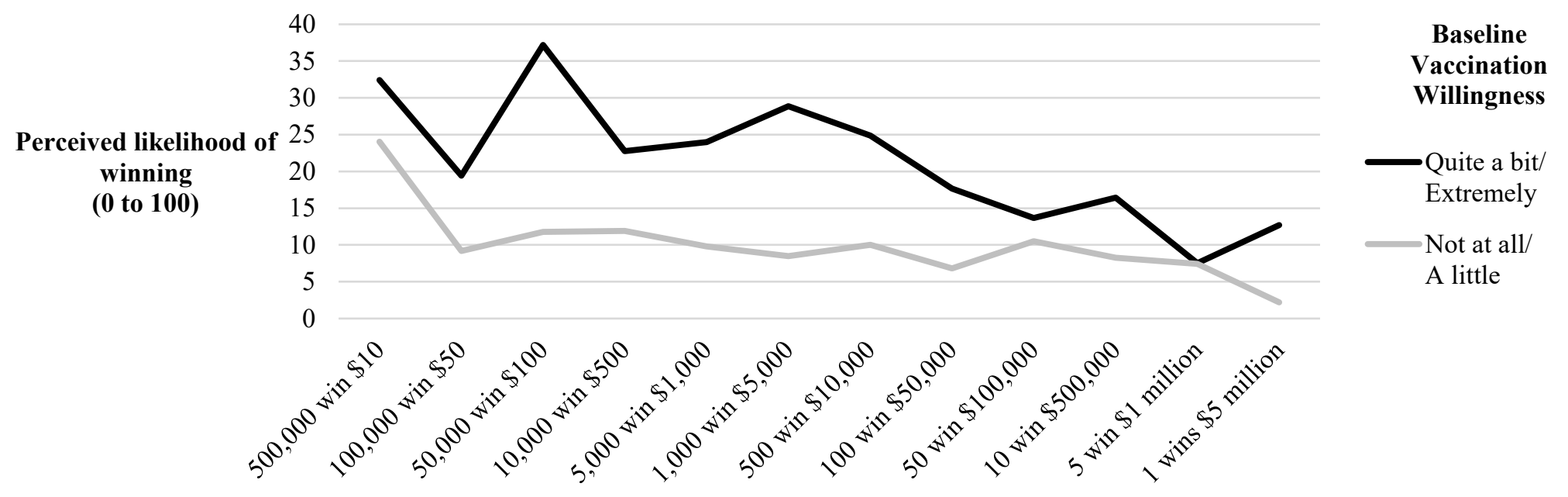

Experimentally-Manipulated Lottery Structure Condition

Figure 1d. Experiment 1, mean anticipated regret as a function of the 12 experimentally-manipulated conditions and baseline vaccination willingness, controlling for gender

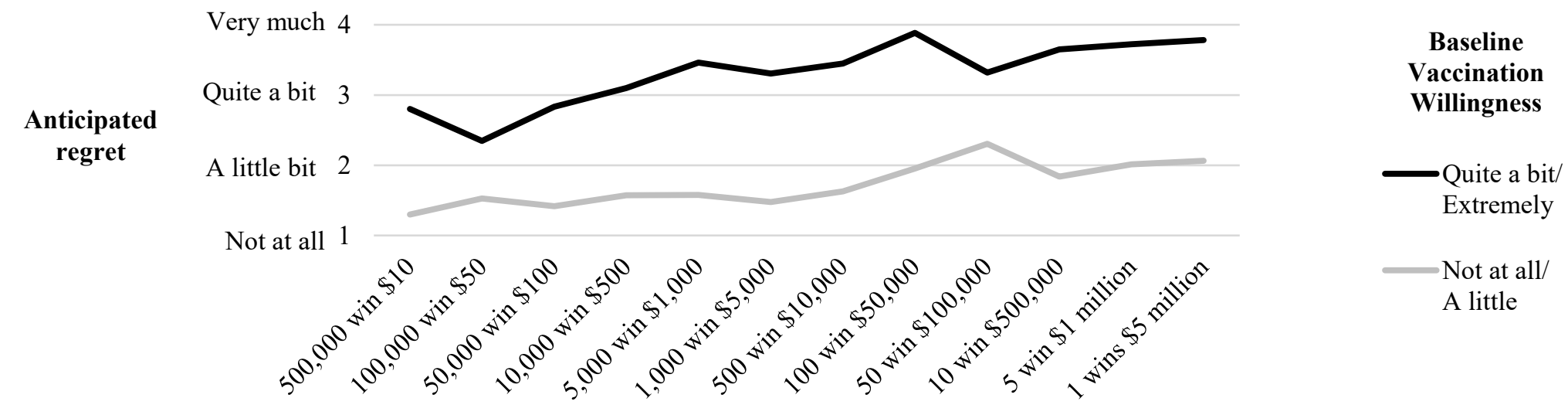

Experimentally-Manipulated Lottery Structure Condition 
Figure 2. Within-subjects choice of preferred vaccine lottery structure, stratified by baseline vaccination willingness, collapsed across Experiments 1 and 2, $n=862$. Percentages are within each category of baseline vaccination willingness

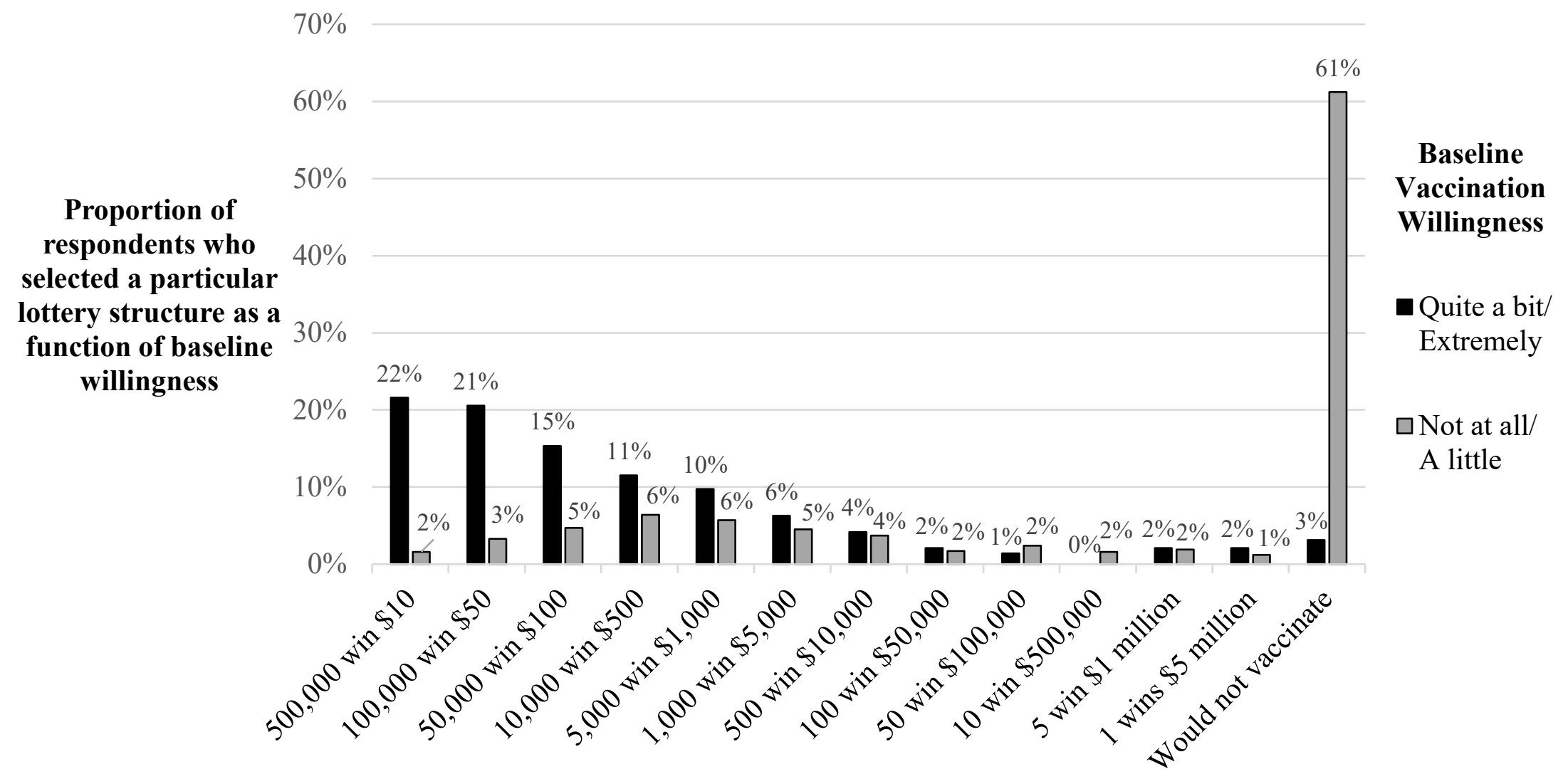

Note: Participants were asked: Some states are giving incentives to adults who receive the COVID-19 vaccine. Imagine that your state has 5 million dollars to give to people who get vaccinated. Which of the following monetary incentives would make you the most likely to get vaccinated? 
Figure 3. Strategy reports for within-subjects rating of the most motivating lottery structure restricted to participants who selected a lottery structure $(n=501)$ and collapsed across Experiments 1 and 2.

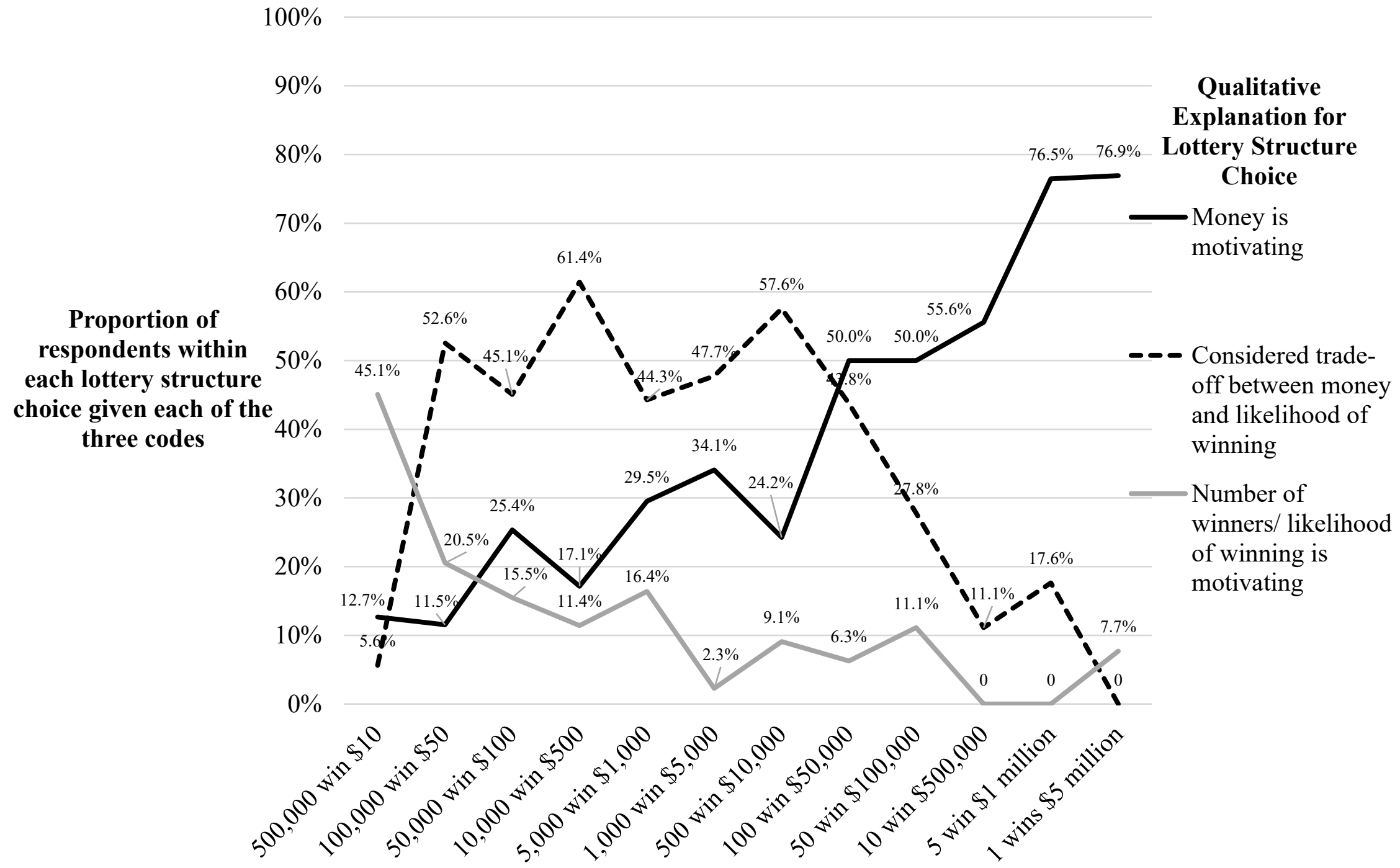

Choice of most motivating lottery structure 